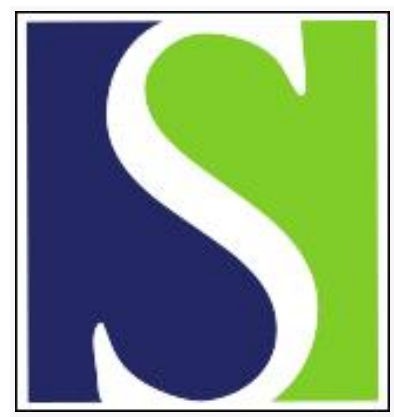

Scand J Work Environ Health 2013;39(4):379-389

https://doi.org/10.5271/sjweh.3346

Published online: 01 Feb 2013, Issue date: 01 Jul 2013

The effect of overcommitment and reward on muscle activity, posture, and forces in the arm-wrist-hand region - a field study among computer workers

by Eijckelhof BHW, Bruno Garza JL, Huysmans MA, Blatter BM, Johnson PW, van Dieën JH, van der Beek AJ, Dennerlein JT

This is the first field study among office workers reporting on the effect of psychosocial and individual stressors on biomechanical loading of the arms, wrists, and hands during computer work. Higher biomechanical loading resulting from these stressors is proposed to lead to arm-wrist-hand symptoms. However, little support for this proposed pathway was found in this study.

Affiliation: VU University Medical Center, Department of Public and Occupational Health, Van der Boechorststraat 7, 1081 BT Amsterdam, The Netherlands. m.huysmans@vumc.nl

Refers to the following text of the Journal: 2000;26(5):398-405

Key terms: arm-wrist-hand; biomechanics; computer worker; effect; ergonomics; exposure assessment; force; muscle activity; office worker; overcommitment; posture; psychosocial

This article in PubMed: www.ncbi.nlm.nih.gov/pubmed/23377125 


\title{
The effect of overcommitment and reward on muscle activity, posture, and forces in the arm-wrist-hand region - a field study among computer workers
}

\author{
by Belinda HW Eijckelhof, MSc, ${ }^{1,2}$ Jennifer L Bruno Garza, BSE, ${ }^{3}$ Maaike A Huysmans, PhD, 1, 2 Birgitte M \\ Blatter, PhD, ${ }^{2,4}$ Peter W Johnson, PhD, ${ }^{5}$ Jaap H van Dieën, PhD, 2, 6 Allard J van der Beek, PhD, ${ }^{1,2}$ Jack $T$ \\ Dennerlein, $P h D^{1,3,7}$
}

\begin{abstract}
Eijckelhof BHW, Bruno Garza JL, Huysmans MA, Blatter BM, Johnson PW, van Dieën JH, van der Beek AJ, Dennerlein JT. The effect of overcommitment and reward on muscle activity, posture, and forces in the armwrist-hand region - a field study among computer workers. Scand J Work Environ Health. 2013;39(4):379-389. doi:10.5271/sjweh.3346
\end{abstract}

Objective Office workers with high levels of overcommitment and low levels of reward are thought to be more prone to arm-wrist-hand symptoms, possibly through a higher internal physical exposure. The aim of this study was to examine the effects of high overcommitment and low reward on (i) forearm muscle activity, (ii) wrist posture and kinematics, and (iii) forces applied to computer input devices during computer work in an actual work setting.

Methods We continuously measured wrist extensor muscle activity, wrist posture and kinematics, and forces applied to the keyboard and mouse for two hours during the daily work of 120 office workers with four different levels of overcommitment and reward (low-high, high-high, low-low, and high-low).

Results Wrist velocities and accelerations in radial-ulnar direction were higher for workers with high compared to low overcommitment, while their wrist range of motion was similar, possibly indicating a higher work pace. Wrist extensor muscle activity and forces applied to the keyboard and mouse were not increased by high overcommitment and/or low reward.

Conclusion Overall, our findings provide little support for the proposed pathway of high overcommitment and low reward in the development of arm-wrist-hand symptoms through a higher internal physical exposure.

Key terms biomechanics; exposure assessment; ergonomics; office worker; psychosocial.

Computer work has become a key element in daily work for many people, and the number of people working with a computer continues to grow. Symptoms in the arm-wrist-hand region are a common problem among computer workers in industrialized as well as developing countries (eg, 1,2). Along with serious consequences for the individual involved, arm-wrist-hand symptoms have also been associated with productivity loss and sick leave $(3,4)$, causing high costs for societies and employers.

Arm-wrist-hand symptoms have a multifactorial origin. Besides physical risk factors, such as posture during computer work (5), work-related psychosocial factors and individual factors have been identified as independent risk factors for developing arm-wrist-hand symptoms (6-8). Potential work-related risk factors of a psychosocial nature include high time pressure, low decision authority, low task variation, job satisfaction, high efforts, and low reward (1, 9-12). Previous disabling symptoms and overcommitment are examples of individual risk factors $(10,12,13)$.

In a recent longitudinal study among computer workers on risk factors for developing arm-wrist-hand symp-

1 Department of Public and Occupational Health and the EMGO Institute for Health and Care Research, VU University Medical Center, Amsterdam, The Netherlands.

2 Body@Work Research Center on Physical Activity, Work and Health, TNO-VU/VUmc, Amsterdam, The Netherlands.

3 Department of Environmental Health, Harvard University, Boston, MA, USA.

4 Netherlands Organization for Applied Scientific Research, TNO, Hoofddorp, The Netherlands.

5 Department of Environmental and Occupational Health Sciences, University of Washington, Seattle, USA.

6 Research institute MOVE, Faculty of Human Movement Sciences, VU University Amsterdam, Amsterdam, The Netherlands.

7 Department of Physical Therapy, Bouvé College of Health Sciences, Northeastern University, 360 Huntington Avenue, Boston, MA, USA.

Correspondence to: Dr. MA Huysmans, VU University Medical Center, Department of Public and Occupational Health, Van der Boechorststraat 7, 1081 BT Amsterdam, The Netherlands [E-mail: m.huysmans@vumc.nl] 
toms, "low reward" and "high overcommitment" turned out to be important, changeable factors that were both significantly related to arm-wrist-hand symptoms (10). However, it is likely that these factors do not work independently in their effect on arm-wrist-hand symptoms. The personality trait overcommitment, which is defined as excessive work-related commitment and a high need for approval (12), might strengthen the effect of low reward and, when both factors act together, the strongest effects on musculoskeletal health can be expected (12).

It has been proposed that work-related psychosocial and individual risk factors lead to upper-extremity symptoms through a higher internal physical exposure during computer use, such as increased muscle activity, higher forces on the keyboard and mouse, more adverse postures, and high repetition of movements $(5,14,15)$, resulting in musculoskeletal damage that could accumulate over time. A recent systematic review (16) has indeed shown that work-related psychosocial stressors led to a higher muscle activity in the forearm region. In addition, other studies found indications for increased forces applied to the keyboard or computer mouse $(15,17-19)$ and more harmful wrist kinematics $(18,19)$ as a result of adverse work-related psychosocial factors. Only one study examined the effects of an individual risk factor on internal physical exposure in the arm-wrist-hand region (20). This study indicated that high motivation, which is a characteristic of the overcommitment personality trait, was associated with increased muscle activity in the wrist extensors during an attention-demanding computer task.

It should be noted that all studies included in the aforementioned systematic review (16) and the studies cited above were performed in laboratory settings. Furthermore, the review indicated that stress induced during realistic computer tasks revealed a smaller increase in muscle activity than stress induced during more constrained simulated computer tasks. Possibly realistic computer tasks - even when performed in a laboratory setting - allow for adaptive motor strategies to cope with the stress. This raises the question whether work-related psychosocial and individual factors indeed result in a higher internal physical exposure in the field. Therefore, to better understand the injury mechanisms of workrelated psychosocial stressors and individual factors in a realistic work setting, field studies on this topic are needed but are currently scarce (16).

Because overcommitment and reward were found to be important risk factors for developing arm-wrist-hand symptoms and field studies on this topic are currently scarce, the aim of the present study was to investigate the effect of overcommitment and reward (and their interaction) on physical exposure of the arms-wristshands (ie, wrist extensor muscle activity, wrist posture and kinematics, and forces applied to the mouse and keyboard) during computer work in a realistic work setting. We hypothesized that computer workers with high overcommitment and/or low reward have higher arm-wrist-hand physical exposures during computer work than those with low overcommitment and/or high reward.

\section{Methods}

\section{Experimental design and set-up}

This study is part of the Predicting Occupational Biomechanics in Office Workers (PROOF) study, which has as overall aim of assessing physical exposure during office work in actual work settings. We selected 120 office workers based on a screening questionnaire, indicating highly contrasting levels of overcommitment and reward. During a day representative of "normal workload", as indicated by the participant, we measured his/her neck-shoulder and forearm muscle activity, postures of the head, neck, torso, and upper extremities, and forces applied to the keyboard and mouse. Only non-obtrusive wireless measurement devices were used. In the present study, the data for the arm-wrist-hand region are presented. Data on the neck-shoulder region have been reported in a separate paper (Bruno Garza JL, Eijckelhof BHW, Huysmans MA, Catalano PJ, Katz JN, Johnson PW, et al. The effect of overcommitment and reward on trapezius muscle activity and shoulder, head, neck, and torso postures during computer use in the field. December 2012, submitted for publication) because indications have been found that the underlying mechanisms for developing neck-shoulder or arm-wristhand symptoms may be different $(17,21)$.

Before the start of the field measurement, the participant completed a consent form. The Harvard School of Public Health Human Subjects Committee, the Medical Ethics Committee of the VU University Medical Center Amsterdam, and the Ethics Committee of the Faculty of Human Movement Sciences of VU University Amsterdam approved all protocols and consent forms.

\section{Selection of participants}

Over 2000 office workers employed at the VU University (8 different departments) and the VU University Medical Center (1 department), in Amsterdam, The Netherlands, were approached as potential participants in the study. In the nine participating departments, each worker received an informative recruitment email and was asked to fill out a short online screening questionnaire containing questions to assess their levels of overcommitment and reward. Overcommitment was 
assessed using a 6-item subscale from "the need for control model" (22) and reward using the reward subscale (11 items) from "the effort-reward imbalance at work model (ERI)" (12).

An average of $35 \%$ (247 out of 707 ) of the approached workers completed the screening questionnaire. Subjects were recruited at department level. Per department, for each participant, the sum scores of overcommitment (range: 6-24) and reward (range: 11-55) were calculated. Subsequently, we selected participants within four different profiles of the most contrasting levels of overcommitment and reward by using the upper and lower tertiles of our high/low definitions, as illustrated in figure $1(23,24)$, with the intention to create contrast within our total group. Because the recruitment of workers was done in waves across departments, the upper and lower tertile values were calculated for each department separately. In this way, the high and low cut-off values were slightly different across departments. Cut-off values of all included departments together were as follows: low overcommitment mean 12.2 (range: 11.0-14.0), high overcommitment mean 14.8 (range: 14.0-16.0), low reward mean 46.4 (range: 38.9-49.9), and high reward mean 52.1 (range: 49.9-53.9).

Of the workers who completed the screening questionnaire, $46 \%$ were willing to participate in the field measurements. Based on the partitioning shown in figure 1, about 30 participants were assigned to each group for a total of 120 subjects. These 120 workers were contacted by telephone for participation in the field measurement phase of the project, but also had to meet the following inclusion criteria, be: (i) an office worker, for whom the main work tasks are computer-related; (ii) healthy (no pain symptoms in the neck, shoulders, arms, wrists, and/or hands for $\geq 1$ week prior to the field measurement); (iii) contracted to work $\geq 20$ hours per week; (iv) comfortable using the mouse with the right hand (table 1).

\section{Data collection and data processing}

Procedure. While the selected 120 participants performed their own work at their own work station, we collected approximately two hours of continuous data on: (i) right and left wrist extensor muscle activity (extensor carpi radialis or ECR); (ii) left and right wrist posture (flexion-extension and ulnar-radial deviation); (iii) keyboard force; and (iv) mouse grip force. See figures $2 \mathrm{a}-\mathrm{c}$ for an illustration of the participant set-up. Additionally, a questionnaire identical to the one used in the Prospective Research on Musculoskeletal Disorders in Office Workers (PROMO) study (25), containing potential confounders, was completed.

Muscle activity. Muscle activity in the left and right ECR was measured using surface electromyography with a wireless logger system (Mega WBA, Mega Electronics LTD, Kupio, Finland). The electrodes (12 millimeter diameter Ambu Bluesensor N-00-S surface electrodes, Ambu, Denmark) were mounted over the muscle bellies of interest with 20 millimeter inter-electrode spacing, following the guidelines for ECR surface electromyography (EMG) of Basmajian (26). Data were recorded at 1000 samples per second after amplification (band-

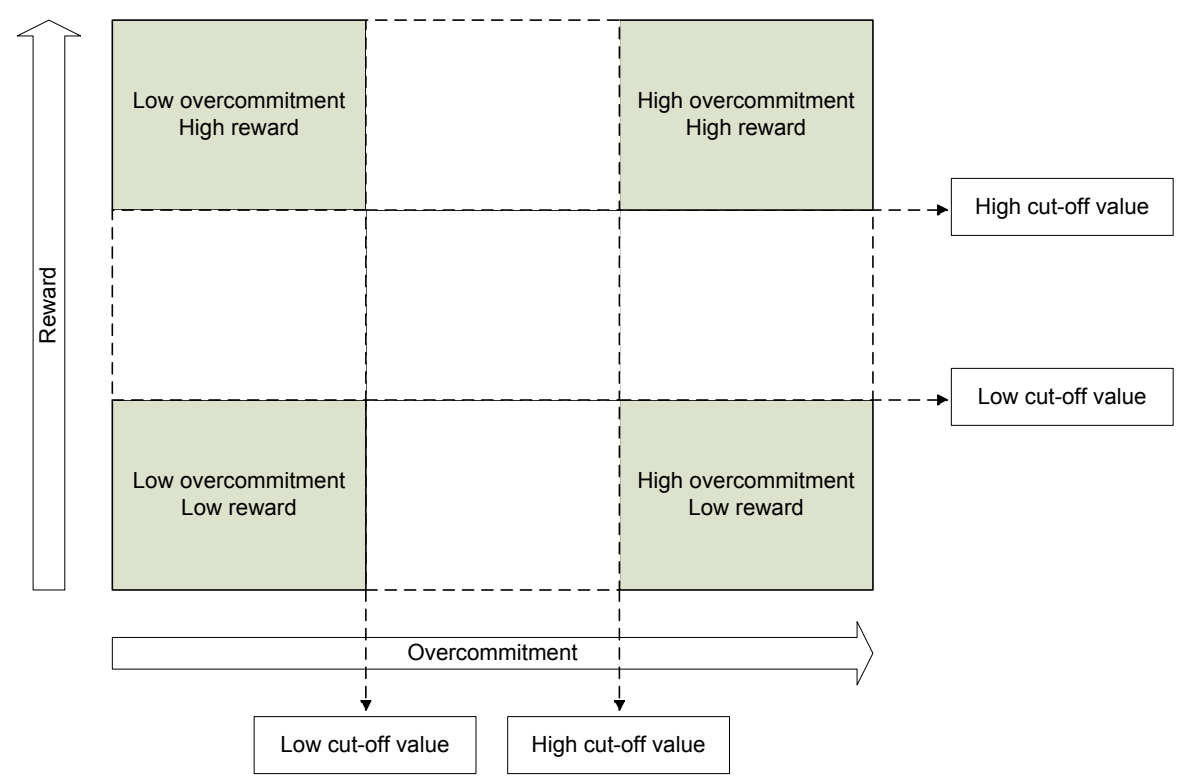

Figure 1. The four defined profiles with most contrasting levels of overcommitment and reward. 


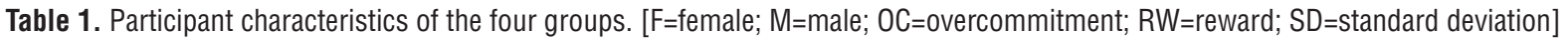

\begin{tabular}{|c|c|c|c|c|c|c|c|c|c|c|c|c|}
\hline & \multicolumn{3}{|c|}{$\begin{array}{c}\text { Age } \\
\text { (years) }\end{array}$} & \multirow{2}{*}{$\begin{array}{c}\begin{array}{c}\text { Gender } \\
(\mathrm{M} / \mathrm{F})\end{array} \\
\mathrm{N}\end{array}$} & \multicolumn{3}{|c|}{$\begin{array}{l}\text { Body height } \\
\text { (cm) }\end{array}$} & \multicolumn{3}{|c|}{$\begin{array}{l}\text { Body weight } \\
\qquad(\mathrm{kg})\end{array}$} & \multirow{2}{*}{$\begin{array}{c}\begin{array}{c}\text { Work history } \\
\text { (years com- } \\
\text { puter work) }\end{array} \\
\mathrm{N}\end{array}$} & \multirow{2}{*}{$\begin{array}{c}\begin{array}{c}\text { Time of } \\
\text { day field } \\
\text { measurement }\end{array} \\
\mathrm{N}\end{array}$} \\
\hline & Mean & $\mathrm{SD}$ & Range & & Mean & SD & Range & Mean & $\mathrm{SD}$ & Range & & \\
\hline $\begin{array}{l}\text { Low OC, high RW } \\
\text { group }(N=31)\end{array}$ & 37 & 13 & $24-62$ & M:10 / F:21 & 177.7 & 9.4 & $163.0-195.0$ & 72.2 & 10.5 & $53.0-91.0$ & $\begin{array}{r}0-5 \text { years: } 14 \\
>5 \text { years: } 17\end{array}$ & $\begin{array}{l}\text { Morning: } 18 \\
\text { Afternoon: } 13\end{array}$ \\
\hline $\begin{array}{l}\text { High OC, high RW } \\
\text { group }(N=29)\end{array}$ & 39 & 12 & 23-62 & $\mathrm{M}: 9$ / F:20 & 173.3 & 10.1 & $157.0-195.0$ & 75.5 & 14.1 & $56.0-112.0$ & $\begin{array}{r}0-5 \text { years: } 12 \\
>5 \text { years: } 17\end{array}$ & $\begin{array}{r}\text { Morning: } 17 \\
\text { Afternoon: } 12\end{array}$ \\
\hline $\begin{array}{l}\text { Low OC, low RW } \\
\text { group }(N=30)\end{array}$ & 40 & 11 & $26-60$ & M:8 / F:22 & 175.0 & 11.1 & $153.0-204.0$ & 72.9 & 14.9 & $49.0-123.0$ & $\begin{array}{r}0-5 \text { years: } 13 \\
>5 \text { years: } 17\end{array}$ & $\begin{array}{r}\text { Morning: } 18 \\
\text { Afternoon: } 12\end{array}$ \\
\hline $\begin{array}{l}\text { High OC, low RW } \\
\text { group }(N=30)\end{array}$ & 43 & 10 & $28-63$ & M:8 / F:22 & 175.2 & 8.9 & $161.0-199.0$ & 75.6 & 13.0 & $54.0-103.0$ & $\begin{array}{l}0-5 \text { years: } 7 \\
>5 \text { years: } 23\end{array}$ & $\begin{array}{r}\text { Morning: } 16 \\
\text { Afternoon: } 14\end{array}$ \\
\hline
\end{tabular}

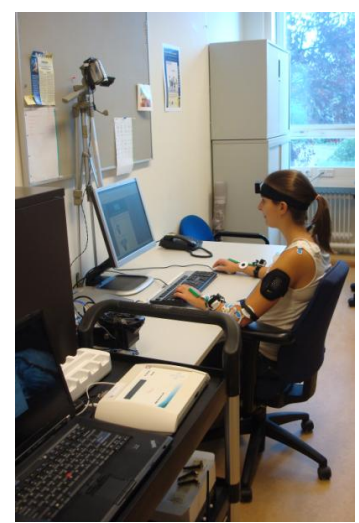

Figure 2a. Set-up overview.

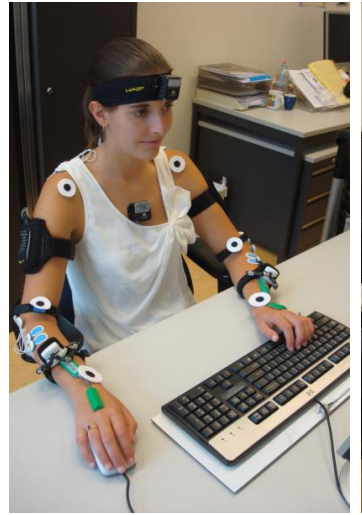

Figure 2b. Participant front view.

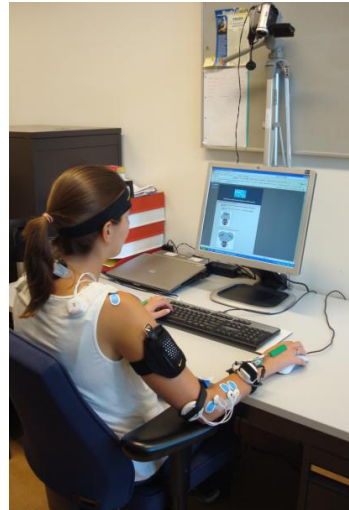

Figure 2. Participant set-up.

Figure 2c. Participant back view.

width of $10-500 \mathrm{~Hz}$ ), then smoothened using a $3 \mathrm{~Hz}$ second-order, zero phase, low-pass Butterworth filter, and down-sampled to 40 samples per second by using a mean filtering procedure.

For each participant, three maximum voluntary contractions (MVC) were collected from the right and left ECR muscle, with one minute of rest in between contractions. MVC were collected by asking the participants to form a fist with their hand and to radially deviate and extend their hand against resistance applied by the experimenter. Each muscle's MVC was the highest 1-second average of the EMG amplitudes collected from the three measurements.

EMG data were expressed as a percentage of a participant's MVC. Median (P50) wrist extensor muscle activity and variability (P90-P10) were calculated for each participant.

Wrist posture and kinematics. We measured left and right wrist flexion-extension and radial-ulnar deviation), using twin axis electrogoniometers (Model SG65, Biometrics Ltd, Gwent, UK), which were mounted over the back of the hand and the forearm with the wrist in a neutral position (ie, hands pronated, middle metacarpal aligned with the midline of the forearm, and backplane of the hand aligned with backplane of the forearm). Data were captured at 1000 samples per second with the same wireless data logging system used to collect the muscle activity data.

The participant's neutral wrist postures were recorded at the beginning of the experiment and all wrist postures were expressed as deviations from the neutral position. Data were filtered through a $5 \mathrm{~Hz}$ second-order, low-pass Butterworth filter and then down-sampled to 40 samples per second.

Median (P50) wrist postures and range of motion (P90-P10) were calculated for each participant and expressed in wrist angles (degrees). Wrist kinematics (ie, wrist joint velocities and accelerations) were calculated by digitally differentiating the posture data and summarized in the root mean squared (RMS) value.

Force. Keyboard force was measured using a keyboard force plate (27), which had three miniature compression load cells (ELFF-B4-10L, Measurement Specialties, Hampton, VA, USA) mounted underneath in a triangular 
pattern. Each participant's own keyboard was placed on top of the keyboard force plate.

Mouse grip force was measured using a modified USB mouse with scroll wheel (Model 3902C693, Microsoft, Inc., Redmond, WA, USA), which had three compression load cells (ELW-D1-10L, Measurement Specialties, Hampton, VA, USA) mounted inside, modelled after the design by Johnson and co-workers (28). The instrumented mouse, designed to be operated with the right hand, measured thumb forces applied to the left side of the mouse. All participants were required to use this force-sensing mouse instead of their own mouse.

Keyboard and the mouse-force data were collected with USB backplanes (NI cDAQ-9172; National Instruments, Austin, TX, USA) and sampled at 10000 samples per second, then low-pass filtered at $20 \mathrm{~Hz}\left(6^{\text {th }}\right.$ order Butterworth filter), down-sampled to 40 samples per second, and normalized to a participant's maximum voluntary force (MVF). For each participant, three MVF were collected per input device, with one minute of rest in between. Maximal typing and mouse force were measured by having the participant maximally press down the "J" key with their right index finger for five seconds and maximally squeeze the mouse for five seconds, respectively. Maximum forces were measured whilst adopting postures similar to those maintained during actual keyboard or mouse work. The MVF values were the highest 1 -second averages of the force signals collected from the three measurements per force-sensing device. For each participant, median (P50) and peak (P90) forces on the keyboard and mouse were calculated.

Computer use and potential confounders. Along with the measurements, we measured computer input device usage using computer interaction monitoring software. From these data we determined non-computer activity and computer activity episodes for each participant. The latter comprised any period within 30 seconds of pressing a key, clicking a button on the mouse, or moving the mouse (29), while the former included any period without computer input device usage for at least 30 seconds (30).

Subject information, such as age, gender, body height, and work history (ie, number of years with computer work), was collected through an online questionnaire. Individual anthropometry was measured, including body weight, shoulder width (distance between the left and right acromial processes of each scapula), arm length (acromion-radiale length), hand length (from the distal wrist crease to the tip of digit III of the hand), and hand width (between the heads of the second and fifth metacarpale). Many of these measures were found to be related to physical exposure parameters in the laboratory $(31,32)$.

\section{Statistical analysis}

Data were checked for a normal distribution and logtransformed if not normally distributed.

We examined the main effects of overcommitment and reward on (i) median (P50) and range (P90-P10) wrist extensor muscle activity and wrist postures, (ii) RMS wrist velocities and accelerations, and (iii) median (P50) and peak (P90) keyboard and mouse forces. In addition, the interaction effect of overcommitment and reward was tested, which provides information on whether a combination of high overcommitment and low reward results in an enlarged effect. Analysis of variance (ANOVA) for repeated measures was used, with overcommitment (low versus high) and reward (high versus low) as between-subject factors and body side (left versus right) as a within-subject factor. For keyboard force or mouse force, univariate ANOVA were used with overcommitment and reward as between-subject factors. The significance level was set at $\mathrm{P} \leq 0.05$.

To adjust for confounding, we added the aforementioned potential confounders (age, gender, work history, body height, body weight, body mass index, shoulder width, arm length, hand length, and hand width) individually as a covariate to our model for each outcome parameter. If the effect size (ie, partial $\eta^{2}$ ) changed by $\geq 10 \%$ then a confounder was considered as relevant and was maintained in the adjusted model. All covariates were continuous variables, except for gender (dichotomous) and work history (categorical). If $\geq 2$ covariates were correlated (ie, $\mathrm{R}^{2}>0.60$ ), only the covariate with the strongest moderating effect was maintained in the adjusted model. An adjusted model for a certain outcome parameter is reported only when $\geq 1$ relevant confounder(s) for that outcome parameter were identified.

\section{Results}

\section{Missing data}

Data of 117 participants were included in the analyses of muscle activity and wrist posture. In the analyses of the wrist kinematics, 116 participants were included, and 114 were included in the analyses of forces on mouse and keyboard data. Data were excluded from the analyses because of technical failures and in one case because only 5 minutes of computer interaction time was measured for that participant.

\section{Wrist extensor muscle activity}

The median extensor carpi radialis muscle activity during computer use was slightly $>5 \% \mathrm{MVC}$ and was not sig- 
nificantly different between participants with low versus high levels of overcommitment or with high versus low levels of reward (table 2). We also examined the results of overcommitment and reward on the $90^{\text {th }}$ and $10^{\text {th }}$ percentiles of muscle activity, but no differences compared to the median values were found and these data were therefore not presented. Furthermore, we did not find any differences in the variability (ie, P90-P10) of ECR muscle activity between any of the groups. In addition, there were no interaction effects between overcommitment and reward for either median muscle activity or variability in muscle activity. No relevant confounders were identified for wrist extensor muscle activity.

\section{Wrist posture and kinematics}

Median wrist posture was around $23^{\circ}$ extension and ranged between $1.8-2.6^{\circ}$ ulnar deviation. There were no significant main effects of overcommitment and reward on median wrist posture (ie, flexion-extension and radial-ulnar deviation) or on wrist range of motion (ie, P90-P10), and no relevant confounders were identified for wrist posture outcomes.

We found a significantly higher velocity and acceleration in radial-ulnar direction for participants with high compared with low overcommitment (table 3 ). However, after controlling for confounding (age, body

Table 2. Results of median muscle activity and variability of the left and right extensor carpi radialis $(\mathrm{N}=117)$. [MVC=maximum voluntary contraction; SE=standard error]

\begin{tabular}{|c|c|c|c|c|c|c|c|c|c|c|c|c|c|c|}
\hline \multirow[t]{3}{*}{$\begin{array}{l}\text { Muscle activity } \\
(\% \text { MVC) }\end{array}$} & \multicolumn{6}{|c|}{ Overcommitment } & \multicolumn{6}{|c|}{ Reward } & \multicolumn{2}{|c|}{$\begin{array}{c}\text { Interaction over- } \\
\text { commitment } \times \text { reward }\end{array}$} \\
\hline & \multicolumn{2}{|c|}{ Low } & \multicolumn{2}{|c|}{ High } & \multirow[t]{2}{*}{ P-value } & \multirow{2}{*}{$\begin{array}{l}\text { Partial } \\
\eta^{2}\end{array}$} & \multicolumn{2}{|c|}{ High } & \multicolumn{2}{|c|}{ Low } & \multirow[t]{2}{*}{ P-value } & \multirow{2}{*}{$\begin{array}{c}\text { Partial } \\
\eta^{2}\end{array}$} & \multirow[t]{2}{*}{ P-value } & \multirow{2}{*}{$\begin{array}{c}\text { Partial } \\
\eta^{2}\end{array}$} \\
\hline & Mean & $\overline{\mathrm{SE}}$ & Mean & $\mathrm{SE}$ & & & Mean & SE & Mean & SE & & & & \\
\hline Median (P50) & 5.0 & 0.3 & 5.5 & 0.3 & 0.24 & 0.012 & 5.2 & 0.3 & 5.4 & 0.3 & 0.61 & 0.002 & 0.68 & 0.001 \\
\hline Variability (P90-P10) & 7.7 & 0.4 & 8.1 & 0.5 & 0.60 & 0.002 & 8.1 & 0.5 & 7.7 & 0.4 & 0.57 & 0.003 & 0.58 & 0.003 \\
\hline
\end{tabular}

Table 3. Results of median wrist posture and kinematics of the left and right sides ( $n=117$ for posture and $n=116$ for velocity and acceleration) and results of adjusted models in case relevant confounding was indicated: age, body height, and body weight were included as covariates for velocity, and work history, body height, and body weight were included as covariates for acceleration. [RMS=root mean square; $\mathrm{SE}=$ standard error.]

\begin{tabular}{|c|c|c|c|c|c|c|c|c|c|c|c|c|c|c|}
\hline & \multicolumn{6}{|c|}{ Overcommitment } & \multicolumn{6}{|c|}{ Reward } & \multicolumn{2}{|c|}{$\begin{array}{c}\text { Interaction over- } \\
\text { commitment } \times \\
\text { reward }\end{array}$} \\
\hline & \multicolumn{2}{|c|}{ Low } & \multicolumn{2}{|c|}{ High } & \multirow[t]{2}{*}{ P-value } & \multirow{2}{*}{$\begin{array}{c}\text { Partial } \\
\eta^{2}\end{array}$} & \multicolumn{2}{|c|}{ High } & \multicolumn{2}{|c|}{ Low } & \multirow[t]{2}{*}{ P-value } & \multirow{2}{*}{$\begin{array}{l}\text { Partial } \\
\eta^{2}\end{array}$} & \multirow[t]{2}{*}{ P-value } & \multirow{2}{*}{$\begin{array}{c}\text { Partial } \\
\eta^{2}\end{array}$} \\
\hline & Mean & SE & Mean & SE & & & Mean & SE & Mean & SE & & & & \\
\hline \multicolumn{15}{|l|}{ Posture (degrees) } \\
\hline \multicolumn{15}{|l|}{ Flexion-extension a } \\
\hline Median (P50) & 22.9 & 1.2 & 23.1 & 1.3 & 0.93 & 0.000 & 22.7 & 1.3 & 23.3 & 1.2 & 0.76 & 0.001 & 0.16 & 0.017 \\
\hline $\begin{array}{l}\text { Range of motion } \\
\text { (P90-P10) }\end{array}$ & 28.3 & 0.9 & 27.5 & 1.0 & 0.53 & 0.004 & 28.0 & 1.0 & 27.7 & 0.9 & 0.83 & 0.000 & 0.88 & 0.000 \\
\hline \multicolumn{15}{|c|}{ Radial-ulnar deviation ${ }^{\mathrm{b}}$} \\
\hline Median (P50) & 2.5 & 0.9 & 1.8 & 0.9 & 0.58 & 0.003 & 1.8 & 0.9 & 2.6 & 0.9 & 0.54 & 0.003 & 0.73 & 0.001 \\
\hline $\begin{array}{l}\text { Range of motion } \\
\text { (P90-P10) }\end{array}$ & 4.2 & 0.6 & 3.6 & 0.6 & 0.48 & 0.004 & 3.8 & 0.6 & 4.0 & 0.5 & 0.84 & 0.000 & 0.43 & 0.006 \\
\hline \multicolumn{15}{|l|}{ Velocity (degrees/s) } \\
\hline \multicolumn{15}{|l|}{ Flexion-extension ${ }^{a}$} \\
\hline RMS & 23.2 & 0.8 & 23.2 & 0.8 & 0.97 & 0.000 & 23.0 & 0.8 & 23.4 & 0.8 & 0.68 & 0.002 & 0.87 & 0.000 \\
\hline \multicolumn{15}{|c|}{ Radial-ulnar deviation b } \\
\hline RMS & 13.4 & 0.4 & 14.6 & 0.4 & $0.03^{c}$ & 0.043 & 14.0 & 0.4 & 14.0 & 0.4 & 0.99 & 0.000 & 0.42 & 0.001 \\
\hline $\mathrm{RMS}^{\mathrm{d}}$ & 13.4 & 0.4 & 14.7 & 0.4 & $0.03^{c}$ & 0.046 & 14.0 & 0.4 & 14.1 & 0.4 & 0.89 & 0.000 & 0.36 & 0.001 \\
\hline \multicolumn{15}{|c|}{ Acceleration (degrees/s²) } \\
\hline \multicolumn{15}{|l|}{ Flexion-extension a } \\
\hline RMS & 306.2 & 12.6 & 310.1 & 13.2 & 0.83 & 0.000 & 309.3 & 13.1 & 307.0 & 12.7 & 0.90 & 0.000 & 0.56 & 0.003 \\
\hline \multicolumn{15}{|c|}{ Radial-ulnar deviation ${ }^{b}$} \\
\hline RMS & 165.4 & 5.9 & 181.8 & 6.0 & $0.05^{c}$ & 0.034 & 175.5 & 6.2 & 171.7 & 5.7 & 0.66 & 0.002 & 0.40 & 0.007 \\
\hline $\mathrm{RMS}^{\mathrm{d}}$ & 166.4 & 6.0 & 180.9 & 6.1 & 0.10 & 0.026 & 176.4 & 6.2 & 170.9 & 5.7 & 0.51 & 0.004 & 0.46 & 0.005 \\
\hline
\end{tabular}


height, body weight, and work history) only wrist velocity (radial-ulnar deviation) remained significantly higher for participants with high overcommitment (table 3 ). No interaction effects between overcommitment and reward were found for any of the wrist posture or kinematic outcome variables.

\section{Forces on input device}

All force variables were non-normally distributed and therefore log-transformed. There were no main effects of overcommitment or reward on the median (P50) keyboard force, and the interaction between overcommitment and reward was not significant. Peak (P90) keyboard forces were significantly affected by reward, with lower peak keyboard forces for participants with low reward as compared to those with high reward: $1.2 \%$ and $1.5 \%$ MVF, respectively (see table 4 ). The main effect of reward remained significant after adjusting for confounders age, gender, hand length, and shoulder width (table 4).

The median force applied to the side of the mouse (in \% MVF) was significantly affected by overcommitment. Participants with low overcommitment squeezed the mouse significantly harder than participants with high overcommitment, $0.3 \%$ and $0.1 \%$ MVF, respectively. However, this effect was no longer significant after adjusting for confounders (including body weight,

Table 4. Results of median and peak keyboard and mouse forces $(n=114)$ and results of adjusted models in case relevant confounding was indicated. Age, gender, hand length, and shoulder width were included as covariates for peak keyboard force, and body weight, body height, and work history were included as covariates for median mouse force. [\% MVF=percentage maximum voluntary force]

\begin{tabular}{|c|c|c|c|c|c|c|c|c|c|c|c|c|c|c|}
\hline & \multicolumn{6}{|c|}{ Over-commitment } & \multicolumn{6}{|c|}{ Reward } & \multicolumn{2}{|c|}{$\begin{array}{l}\text { Interaction over- } \\
\text { commitment } \times \\
\text { reward }\end{array}$} \\
\hline & \multicolumn{2}{|c|}{ Low } & \multicolumn{2}{|c|}{ High } & \multirow[t]{2}{*}{$P$-value } & \multirow{2}{*}{$\begin{array}{c}\text { Partial } \\
\eta^{2}\end{array}$} & \multicolumn{2}{|c|}{ High } & \multicolumn{2}{|c|}{ Low } & \multirow[t]{2}{*}{$P$-value } & \multirow{2}{*}{$\begin{array}{c}\text { Partial } \\
\eta^{2}\end{array}$} & \multirow[t]{2}{*}{ P-value } & \multirow{2}{*}{$\begin{array}{c}\text { Partial } \\
\eta^{2}\end{array}$} \\
\hline & Median & $\overline{\text { Range }}$ & Median & Range & & & Median & $\overline{\text { Range }}$ & Median & Range & & & & \\
\hline \multicolumn{15}{|l|}{$\begin{array}{l}\text { Keyboard force } \\
\text { (\% MVF) }\end{array}$} \\
\hline Median (P50) & 0.0 & $0.0-2.8$ & 0.0 & $0.0-12.1$ & 0.83 & 0.000 & 0.0 & $0.0-2.8$ & 0.0 & $0.0-2.8$ & 0.80 & 0.001 & 0.45 & 0.005 \\
\hline Peak (P90) & 1.4 & $0.0-7.5$ & 1.3 & $0.1-18.2$ & 0.48 & 0.004 & 1.5 & $0.4-7.1$ & & $0.0-18.2$ & $0.04^{a}$ & 0.036 & 0.31 & 0.009 \\
\hline Peak (P90) b & 1.4 & $0.0-7.5$ & 1.3 & $0.1-18.2$ & 0.54 & 0.004 & 1.5 & $0.4-7.1$ & 1.2 & $0.0-18.2$ & $0.02^{a}$ & 0.048 & 0.34 & 0.009 \\
\hline \multicolumn{15}{|l|}{$\begin{array}{l}\text { Mouse force } \\
\text { (\% MVF) }\end{array}$} \\
\hline Median (P50) & 0.3 & $-0.2-2.6$ & 0.1 & $-0.3-4.0$ & $0.02^{\mathrm{a}}$ & 0.051 & 0.3 & $-0.2-4.0$ & 0.1 & $-0.3-2.6$ & 0.95 & 0.000 & $0.04^{\mathrm{a}}$ & 0.044 \\
\hline Median (P50) ${ }^{b}$ & 0.3 & $-0.2-2.6$ & 0.1 & $-0.3-4.0$ & 0.08 & 0.032 & 0.3 & $-0.2-4.0$ & 0.1 & $-0.3-2.6$ & 0.92 & 0.000 & $0.03^{a}$ & 0.048 \\
\hline Peak (P90) & 1.8 & $0.4-9.3$ & 2.2 & $0.8-9.3$ & 0.31 & 0.009 & 1.8 & $0.4-9.3$ & 2.2 & $0.8-8.3$ & 0.16 & 0.018 & 0.17 & 0.017 \\
\hline
\end{tabular}

a $P \leq 0.05$.

${ }^{\mathrm{b}}$ Results when adjusted for confounding.

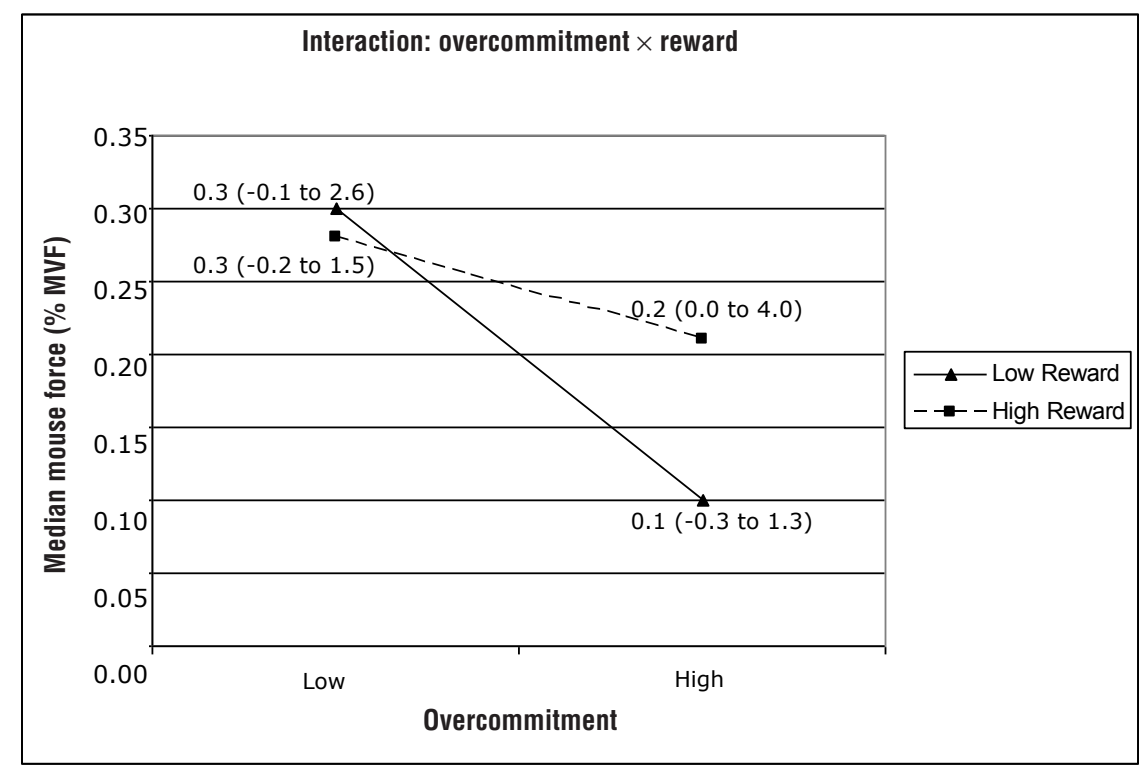

Figure 3. Interaction between overcommitment and reward for median mouse force [percentage maximum voluntary force (\% MVF)] with the triangles representing the values for low reward and the squares the values for high reward. 
body height, and work history) (table 4). A significant interaction was also found between overcommitment and reward for median mouse force, which remained after adjusting for confounders (table 4). Participants with a combination of high overcommitment and low reward showed the lowest mouse squeezing force (figure 3).

\section{Discussion}

The aim of this study was to examine whether high overcommitment and/or low reward lead to increased internal physical exposure during computer work in an actual work setting. We expected that workers with high overcommitment and/or low reward would have higher wrist extensor muscle activity, more extreme wrist postures, higher wrist velocities and accelerations, and higher forces applied to the keyboard and mouse.

Only few of our expectations were supported by the data. As we expected, wrist velocity and acceleration in radial-ulnar direction were higher for highly versus low overcommitted workers. However, we found neither a higher median wrist extensor muscle activity nor more extreme postures for those with high overcommitment and/or low reward as was expected. Results of mouse and keyboard forces were in contrast with our expectations. We found indications for lower median mouse force for workers with high overcommitment than for workers with low overcommitment, and peak keyboard force was lower for individuals with low reward as compared to those with high reward. Although the hypothesized pathway of arm-wrist-hand symptom development due to workplace and individual stressors via an increased internal loading received only limited support in this study, more evidence for this pathway appears to exist for neck-shoulder symptoms. In line with other studies $(20,33)$, we found higher trapezius activity for workers with a combination of high overcommitment and low reward and a main effect of overcommitment on median trapezius muscle activity, indicating a higher trapezius activity for those who are overcommitted, as reported by Bruno-Garza and co-workers (Bruno Garza JL, Eijckelhof BHW, Huysmans MA, Catalano PJ, Katz JN, Johnson PW, et al. The effect of overcommitment and reward on trapezius muscle activity and shoulder, head, neck, and torso postures during computer use in the field. December 2012, submitted for publication).

In line with our hypotheses, wrist velocity and acceleration in radial-ulnar direction were higher for workers with high compared to low overcommitment. Arm-wrist-hand symptoms can originate from overexertion of forearm muscles controlling this movement or from increased friction of tendons and nerves in the carpal tunnel $(34,35)$. High wrist movement velocity and acceleration were indicated as the risk factors that were most consistently associated with arm-wrist-hand musculoskeletal disorders (36). Higher wrist velocity and acceleration in combination with a similar range of motion in the high and low overcommitment groups, may indicate that the highly overcommitted workers had a higher work pace. A higher work pace might increase physical exposure in the arm-wrist-hand region through increased forearm muscle activity as was also found in a recent paper reviewing experimental laboratory studies on this topic (16). However, in the present study wrist extensor muscle activity was not higher among workers with high overcommitment. This may be because the muscle we measured, the ECR, is primarily a wrist extensor and, to a lesser extent, also a radial deviator of the wrist.

Unexpectedly, we found that workers with low overcommitment showed indications for a higher median mouse force than workers with high overcommitment, particularly when these workers experienced low reward as well. This finding can be interpreted in different ways. First, it could be that workers with low overcommitment squeezed the mouse harder than those with high overcommitment. Second, it could be that the workers in both groups squeezed the mouse equally, but that the low overcommitted group worked with the mouse for a larger percentage of the measurement time (we took the median of the mouse force during total computer interaction time, ie, keyboard, mouse and idle activity). However, duration of mouse use was comparable in both overcommitment groups. A third explanation could be that the lower mouse forces (\% MVF) among workers with high overcommitment were the result of a higher MVF and not because of higher absolute forces on the mouse. However, the statistical differences between groups were similar for absolute mouse forces (Newton) and mouse force expressed in \% MVF. Hence, it seems that workers with overcommitment indeed used lower forces when using the mouse, possibly because they make faster mouse movements and/or they make quicker changes between the mouse and the keyboard.

Keyboard force results were also unexpected. We found that peak keyboard force was higher for individuals with high reward, indicating that these workers occasionally pressed harder on the keyboard than workers with low reward. However, we do not have a possible explanation for this result.

Force values in the present study were small. To give an indication of the magnitude of the presented forces in \% MVF: median mouse forces were around $0.1 \mathrm{~N}$, all peak mouse forces were between $0.9-1.0 \mathrm{~N}$, all median keyboard forces around $0.0 \mathrm{~N}$, and all peak keyboard forces between $0.5-0.6 \mathrm{~N}$. The reason for these relatively low force values was that median and peak 
forces were calculated across all computer activities, ie, keyboard, mouse and idle activity to reflect exposure during computer use. Negative values in the ranges of mouse force (table 4) may appear strange, but were the result of random error of our measurement device. When the mouse was untouched (ie, zero mouse force), fluctuations in mouse force were equally distributed around zero.

In this study, we found small effects of high overcommitment and no important effects of low reward. Besides the possibility that overcommitment and reward do not really increase internal physical exposure of the arms-wrists-hands, it is also possible that this is caused by the way we measured these concepts. Even though we aimed for high contrasts between the high and low overcommitment and reward groups, the sum scores of both groups were rather close together and indicated a ceiling effect for reward. Possibly the discriminant validity of the ERI at work model was insufficient for our study population, consisting of office workers who were relatively highly educated. The population, in which the ERI model was originally tested, was much more heterogeneous (12). Stronger contrasts between the groups could have resulted in stronger effects of high overcommitment and low reward than we found in our study. We cannot fully rule out the possibility that the limited contrast between groups was the result of selection bias, because we do not know the profiles of reward and overcommitment of the workers who did not respond to the screening questionnaire. However, there were no indications of selection bias for those who completed the screening questionnaire and were willing to participate in the study; their levels of reward and overcommitment were similar to those of individuals who answered the screening questionnaire but were unwilling to participate. Another possible reason for finding small effects of high overcommitment and no important effects of low reward might be the participant's level of perceived stress during the measurement, which was "lower compared to a usual working day" for 53 participants. For the other participants their level of perceived stress was "similar", except for two participants who indicated perceiving "higher" stress compared to a normal working day."

Several strengths of the present study are noteworthy. This is the first study measuring many different physical exposure parameters during two hours of computer work while participants actually performed their own work. We used non-obtrusive wireless measurement devices and as a result of this we were able to perform the measurements in the workers' normal work environment. By this means, the stressors of interest are more natural than the induced stressors in experimental studies. Also, the number of participants enrolled in this study was relatively high.
However, some limitations should also be mentioned. A first limitation of this study is that we assumed that the levels of overcommitment and reward at the time of participant selection were representative of the stress experienced during the physical exposure measurements. However, the questions in the overcommitment and reward scales refer to a more general state of stress, experienced during a longer period of time, and may vary over days. As a consequence, random noise will have been induced, diminishing the contrasts between groups and resulting in smaller effects. Although we were partly able to overcome this by using the highest and lowest tertiles, it still might have attenuated our results. Second, we only looked at physical exposure during computer use and were not able to collect sufficient data on non-computer use while at work. Results of physical exposure during non-computer use might be important for understanding the development of armwrist-hand symptoms since variation in biomechanical exposure is thought to be beneficial for musculoskeletal health and might be a remedy against musculoskeletal symptoms (37). Third, it remains to be seen if our conclusions can be generalized to other work settings and populations. The studied stressors and tasks are natural and the study population is representative of computer workers, but the measurements were performed in the public sector only. More extreme levels of overcommitment and reward can be expected especially in the private sector, and possibly stronger effects of high overcommitment and low reward might be found. Lastly, because this study has many outcome parameters, our finding that highly overcommitted workers show higher wrist movement velocities and accelerations could be based on chance and should therefore be confirmed in future studies.

In our study, we focused on effects of two different psychosocial stressors (and their interaction) to evaluate physical exposure during computer work because these psychosocial stressors were found to be the strongest risk factors for developing arm-wrist-hand symptoms. However, in a realistic work setting, multiple psychosocial and individual factors are present and because effect sizes of single effects are small, we intent to test the combined effect of multiple factors in a follow-up study. In future studies, it is also of interest to examine work pace (eg, typing speed, mouse movement velocity, and productivity) in addition to physical exposure, to be able to link both constructs and thereby possibly shed light on the underlying mechanisms in the development of musculoskeletal injury. For the development of intervention programs that prevent musculoskeletal injury, it is important to know whether work-related psychosocial and individual risk factors increase physical exposure directly or indirectly through adapted work patterns, such as an increased work pace. 


\section{Concluding remarks}

In conclusion, workers with high overcommitment show higher wrist velocity and acceleration in the radial-ulnar direction during computer work, possibly as a result of a higher work pace. Even though this finding provides some support for the hypothesis that arm-wrist-hand symptoms may develop through a higher physical load, no other physical load parameters were increased by high overcommitment and/or low reward. Unexpectedly, we found that workers with low reward squeezed the mouse less firmly compared to workers with high reward. Overall, our findings provide little support for the proposed pathway of high overcommitment and low reward in the development of arm-wrist-hand symptoms through a higher internal physical exposure.

\section{Acknowledgments}

This study was supported by the $\mathrm{EMGO}^{+}$Travel Grant of the $\mathrm{EMGO}^{+}$Institute for Health and Care Research, VU University Medical Center, Amsterdam, The Netherlands, and was funded in part by the CDC/NIOSH grant R01-0H-08781 (Principle Investigator: Dennerlein). The authors would like to thank Sachin Raina and Patrik Rynell for their contributions to the data collection and analysis in this study.

\section{References}

1. Klussmann A, Gebhardt H, Liebers F, Rieger MA. Musculoskeletal symptoms of the upper extremities and the neck: a cross-sectional study on prevalence and symptom-predicting factors at visual display terminal (VDT) workstations. BMC Musculoskelet Disord. 2008;9:96. http:// dx.doi.org/10.1186/1471-2474-9-96.

2. Ranasinghe P, Perera YS, Lamabadusuriya DA, Kulatunga S, Jayawardana N, Rajapakse S, Katulanda P. Work related complaints of neck, shoulder and arm among computer office workers: a cross-sectional evaluation of prevalence and risk factors in a developing country. Environ Health. 2011;10:70. http://dx.doi.org/10.1186/1476-069X-10-70.

3. Hagberg M, Vilhemsson R, Tornqvist EW, Toomingas A. Incidence of self-reported reduced productivity owing to musculoskeletal symptoms: association with workplace and individual factors among computer users. Ergonomics. 2007;50(11):1820-34. http://dx.doi. org/10.1080/00140130701674539.

4. van den Heuvel SG, IJmker S, Blatter BM, de Korte EM. Loss of productivity due to neck/shoulder symptoms and hand/arm symptoms: results from the PROMO-study. J Occup Rehabil. 2007;17(3):370-82. http://dx.doi.org/10.1007/s10926-007- 9095-y.

5. Marcus M, Gerr F, Monteilh C, Ortiz DJ, Gentry E, Cohen $\mathrm{S}$, et al. A prospective study of computer users: II. Postural risk factors for musculoskeletal symptoms and disorders. Am J Ind Med. 2002;41(4):236-49. http://dx.doi.org/10.1002/ ajim.10067.

6. Bongers PM, IJmker S, van den Heuvel S, Blatter BM. Epidemiology of work related neck and upper limb problems: psychosocial and personal risk factors (part I) and effective interventions from a bio behavioural perspective (part II). J Occup Rehabil. 2006;16(3):279-302. http://dx.doi. org/10.1007/s10926-006-9044-1.

7. Bongers PM, Kremer AM, ter Laak J. Are psychosocial factors, risk factors for symptoms and signs of the shoulder, elbow, or hand/wrist?: A review of the epidemiological literature. Am J Ind Med. 2002;41(5):315-42. http://dx.doi.org/10.1002/ ajim. 10050 .

8. Hauke A, Flintrop J, Brun E, Rugulies R. The impact of workrelated psychosocial stressors on the onset of musculoskeletal disorders in specific body regions: A review and meta-analysis of 54 longitudinal studies. Work \& Stress 2011;25(3):243-56. http://dx.doi.org/10.1080/02678373.2011.614069.

9. Eltayeb S, Staal JB, Hassan A, de Bie RA. Work related risk factors for neck, shoulder and arms complaints: a cohort study among Dutch computer office workers. J Occup Rehabil. 2009;19(4):315-22. http://dx.doi.org/10.1007/s10926-0099196-x.

10. Huysmans M, IJmker S, Blatter B, Knol D, van Mechelen W, Bongers $\mathrm{P}$, et al. The relative contribution of work exposure, leisure time exposure, and individual characteristics in the onset of arm-wrist-hand and neck-shoulder symptoms among office workers. Int Arch Occup Environ Health. 2012;85(6):651-66. http://dx.doi.org/10.1007/s00420-0110717-5.

11. Karasek R, Brisson C, Kawakami N, Houtman I, Bongers P, Amick B. The Job Content Questionnaire (JCQ): an instrument for internationally comparative assessments of psychosocial job characteristics. J Occup Health Psychol. 1998;3(4):322-55. http://dx.doi.org/10.1037/1076-8998.3.4.322.

12. Siegrist J, Starke D, Chandola T, Godin I, Marmot M, Niedhammer I, et al. The measurement of effort-reward imbalance at work: European comparisons. Soc Sci Med. 2004;58(8):1483-99. http://dx.doi.org/10.1016/S02779536(03)00351-4

13. van den Heuvel SG, van der Beek AJ, Blatter BM, Bongers PM. Workstyle and overcommitment in relation to neck and upper limb symptoms. Int J Behav Med. 2007;14(1):12-20. http://dx.doi.org/10.1007/BF02999223.

14. Harrington CB, Feuerstein M. Workstyle in office workers: ergonomic and psychological reactivity to work demands. J Occup Environ Med. 2010;52(4):375-82. http://dx.doi. org/10.1097/JOM.0b013e3181d5e51d.

15. Visser B, de Looze M, De Graaff M, van Dieen J. Effects of precision demands and mental pressure on muscle activation and hand forces in computer mouse tasks. Ergonomics. 2004;47(2):202-17. http://dx.doi.org/10.1080/00140130310 


\section{7.}

16. Eijckelhof BHW, Huysmans MA, Bruno Garza JL, Blatter BM, van Dieen JH, Dennerlein JT, et al. The effects of workplace stressors on muscle activity in the neck-shoulder and forearm muscles during computer work: a systematic review and meta-analysis. Eur J App Physio. 2013 Jan 28; In press.

17. Bloemsaat JG, Meulenbroek RGJ, van Galen GP. Differential effects of mental load on proximal and distal arm muscle activity. Exp Brain Res. 2005;167(4):622-34. http://dx.doi. org/10.1007/s00221-005-0066-2.

18. Hughes LE, Babski-Reeves K, Smith-Jackson T. Effects of psychosocial and individual factors on physiological risk factors for upper extremity musculoskeletal disorders while typing. Ergonomics. 2007;50(2):261-74. http://dx.doi. org/10.1080/00140130601049378.

19. Wahlstrom J, Hagberg M, Johnson PW, Svensson J, Rempel D. Influence of time pressure and verbal provocation on physiological and psychological reactions during work with a computer mouse. Eur J Appl Physiol. 2002;87(3):257-63. http://dx.doi.org/10.1007/s00421-002-0611-7.

20. Waersted M, Westgaard RH. Attention-related muscle activity in different body regions during VDU work with minimal physical activity. Ergonomics. 1996;39(4):661-76. http://dx.doi.org/10.1080/00140139608964488.

21. IJmker S, Huysmans MA, Blatter BM, van der Beek AJ. Should office workers spend fewer hours at their computer? A systematic review of the literature. Occup Environ Med. 2007;64:211-222. http://dx.doi.org/10.1136/ oem.2006.026468.

22. Siegrist J. Adverse health effects of high-effort/low-reward conditions. J Occup Health Psychol. 1996;1(1):27-41. http:// dx.doi.org/10.1037/1076-8998.1.1.27.

23. Bosma H, Peter R, Siegrist J, Marmot M. Two alternative job stress models and the risk of coronary heart disease. Am J Public Health. 1998;88(1):68-74. http://dx.doi.org/10.2105/ AJPH.88.1.68.

24. Ostry AS, Kelly S, Demers PA, Mustard C, Hertzman C. A comparison between the effort-reward imbalance and demand control models. BMC Public Health. 2003 27;3:10. http:// dx.doi.org/10.1186/1471-2458-3-10

25. IJmker S, Blatter BM, van der Beek AJ, van Mechelen W, Bongers PM. Prospective research on musculoskeletal disorders in office workers (PROMO): study protocol. BMC Musculoskelet Disord. 2006;7:55. http://dx.doi. org/10.1186/1471-2474-7-55.

26. Basmajian JV. Biofeedback; Principles and practice for clinicians. Baltimore: Willams \& Wilkins; 1989.
27. Asundi K, Johnson PW, Dennerlein JT. Inertia artefacts and their effect on the parameterisation of keyboard reaction forces. Ergonomics. 2009;52(10):1259-64. http://dx.doi. org/10.1080/00140130903023691.

28. Johnson PW, Hagberg M, Hjelm EW, Rempel D. Measuring and characterizing force exposures during computer mouse use. Scand J Work Environ Health. 2000;26(5):398-405. http:// dx.doi.org/10.5271/sjweh.560.

29. Chang CH, Johnson PW, Dennerlein JT. A wide range of activity duration cutoffs provided unbiased estimates of exposure to computer use. J Occup Environ Hyg. 2008;5(12):790-6. http:// dx.doi.org/10.1080/15459620802491158.

30. Hwang YH, Chen YT, Yeh JY, Liang HW. Effects of passive computer use time and non-computer work time on the performance of electronic activity monitoring. Ergonomics. 2010;53(10):1254-62. http://dx.doi.org/10.1080/00140139. 2010.512985 .

31. Karlqvist L, Hagberg M, Selin K. Variation in upper limb posture and movement during word processing with and without mouse use. Ergonomics. 1994;37(7):1261-7. http:// dx.doi.org/10.1080/00140139408964904.

32. Won EJ, Johnson PW, Punnett L, Dennerlein JT. Upper extremity biomechanics in computer tasks differ by gender. J Electromyogr Kinesiol. 2009;19(3):428-36. http://dx.doi. org/10.1016/j.jelekin.2007.11.012.

33. Willmann M, Bolmont $\mathrm{B}$. The trapezius muscle uniquely lacks adaptive process in response to a repeated moderate cognitive stressor. Neurosci Lett. 2012;506(1):166-9. http://dx.doi. org/10.1016/j.neulet.2011.10.073.

34. Visser B, van Dieen JH. Pathophysiology of upper extremity muscle disorders. J Electromyogr Kinesiol. 2006;16(1):1-16. http://dx.doi.org/10.1016/j.jelekin.2005.06.005.

35. Lopes MM, Lawson W, Scott T, Keir PJ. Tendon and nerve excursion in the carpal tunnel in healthy and CTD wrists. Clin Biomech. 2011;26(9):930-6. http://dx.doi.org/10.1016/j. clinbiomech.2011.03.014.

36. Nordander C, Ohlsson K, Akesson I, Arvidsson I, Balogh I, Hansson GA, et al. Exposure-response relationships in work-related musculoskeletal disorders in elbows and hands - A synthesis of group-level data on exposure and response obtained using uniform methods of data collection. Appl Ergon. 2013;44(2):241-53. http://dx.doi.org/10.1016/j. apergo.2012.07.009.

37. Mathiassen SE. Diversity and variation in biomechanical exposure: what is it, and why would we like to know? Appl Ergon. 2006;37(4):419-27. http://dx.doi.org/10.1016/j. apergo.2006.04.006.

Received for publication: 11 July 2012 